\title{
Adaptation to curvature: Eye movements or neural curvature analyzers?
}

\author{
MARK W. VERNOY \\ University of California, Irvine, California 92664
}

\begin{abstract}
Three experiments were conducted in an attempt to discriminate between an eye-movement theory and a neural curvature analyzer theory of visual adaptation to curvature. Ninety university students served as subjects and were required to inspect stimulus lines presented as (a) curved line pairs, (b) single curved lines, (c) curved line stereograms portraying curved lines concave up, to the right, or toward the subject, or (d) random-dot stereograms portraying curved lines concave up, to the right, or toward the subject. The results of the first two experiments indicate that subjects can readily adapt to the curvature in pairs of lines of opposite curvature presented in different parts of the same or opposite retinas. These results contradict the eye-movement theory of adaptation to curvature. In the third experiment, adaptation to curvature was recorded for curved lines presented as line stereograms and random-dot stereograms. It was concluded that presently the neural curvature analyzer theory of adaptation to curvature best explains the results of these three experiments.
\end{abstract}

James J. Gibson (1933) was the first to report that prolonged inspection of a curved line caused the line to be perceived as less curved. He also described a negative aftereffect which caused objectively straight lines to be perceived as curved in the direction opposite to that of the inspection line. To explain this effect. Gibson posited a normalization process. He stated that this process may be akin to sensory adaptation (e.g., color adaptation). Color adaptation caused a colored stimulus field to become less saturated and approach the color gray, which is a perceptual norm for color. Gibson proposed that it was conceivable that curved lines might also undergo adaptation and approach the perceptual norm of rectilinearity.

Since Gibson's (1933) paper, several other researchers have proposed theories to explain adaptation to curvature and the subsequent negative aftereffect (Coltheart, 1971; Coren \& Festinger, 1967; Kohler \& Wallach, 1944; Over, 1971). Kohler and Wallach (1944) described adaptation to curvature as a special case of tigural aftereffects resulting from cortical satiation. Coren and Festinger (1967) postulated that adaptation might not be adaptation to curvature at all, but a decrement in a curvature

This research is based on a dissertation (Vernoy, 1975) submitted to the University of California. Irvine, in partial fulfillment of the requirements for the $\mathrm{PhD}$ degree. The author wishes to thank Myron L. Braunstein for his invaluable comments and assistance in the preparation of this report. The author also wishes to express his appreciation of the research assistance by Kenneth $R$. Stern. This research was supported in part by Public Health Service Predoctoral Research Fellowship 1 FO1 MH58071-01 to the author. The special projection and viewing facilities used for these experiments were provided by National Science Foundation Grant GB-40207 to Myron L. Braunstein. Requests for reprints should be sent to Mark W. Vernoy. who is now at the Vision Branch. Naval Submarine Medical Research Laboratory, Box 900 . Naval Submarine Base New London, Groton. Connecticut 06340. illusion caused by eye movements. Coren and Festinger reported that subjects initially overestimated the curvature of an arc. Adaptation to curvature was then not really adaptation to curvature but a decrement in the illusion which caused this initial overestimation of curvature. Coltheart (1971) and Over (1971) have proposed adaptation of neural feature analyzers in the visual cortex as the mechanism for adaptation to curvature.

\section{EXPERIMENT I}

Gibson (1933) stated that his subjects reported adaptation to curvature for several different orientations of curved lines viewed simultaneously. If adaptation to curvature is actually a decrement in a curvature illusion caused by eye movements, as Coren and Festinger (1967) postulate, then Gibson's subjects should have had to track the different curves separately in order to adapt to the curvature in all the curves. It is not clear from Gibson's (1933) report exactly how the curves were oriented. However, since it is not physically possible to track lines of opposite curvature at the same time, a subject would have to track each line separately by bringing each curve in turn into the fovea. This multiple tracking in opposite directions might cause counteradaptation to one direction of curvature while causing adaptation to another direction of curvature. The hypothesis tested in Experiment $\mathbf{I}$ is that adaptation can occur to differentially curved lines projected onto noncorresponding parts of the same or opposite retinas.

\section{Method}

Subjects. The subjects were 40 introductory psychology students who participated in this experiment to fulfill a course requirement, Additional subjects (6) were run or partly run. but had to be dropped due to failure to follow instructions (3), failure to have 


\begin{tabular}{|c|c|c|c|c|c|c|c|}
\hline \multirow{2}{*}{$\begin{array}{l}\text { INSPECTION } \\
\text { TMPE }\end{array}$} & \multirow{2}{*}{ TEST } & \multicolumn{3}{|c|}{ Wosfection stimuer } & \multicolumn{3}{|c|}{ TEST STINUT } \\
\hline & & LEFT & neart & PUSED & LET & niem & Pused \\
\hline \multirow{4}{*}{ MONOCUNAR } & \multirow{2}{*}{ INTEROCULAR } & $\theta$ & $\cdot$ & $\theta$ & $\cdot$ & $\mathrm{H}$ & $H$ \\
\hline & & $\mu$ & • & K & • & $H$ & $H$ \\
\hline & \multirow{2}{*}{ INTRAOCULN } & $\theta$ & - & $\theta$ & $H$ & - & $H$ \\
\hline & & H & • & K & $H$ & - & $H$ \\
\hline \multirow{4}{*}{ BImocuen } & \multirow[b]{2}{*}{ WTEROCULAR } & 6 & .) & $\theta$ & 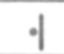 & 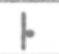 & $H$ \\
\hline & & r & f & K & 1 & $p$ & $H$ \\
\hline & \multirow{2}{*}{ WTRAOCULAR } & 6 & ) & $\theta$ & $p$ & d & $H$ \\
\hline & & r & 1 & H & $p$ & $d$ & $\mathrm{H}$ \\
\hline
\end{tabular}

Figure 1. Experimental stimuli used in Experiment I. (Additional test stimuli were curved lines in the same positions as the straight lines shown in the figure.)
$20 / 40$ visual acuity (2) (Bausch $\&$ Lomb direct reading test chart $20 / 20$ line at $10 \mathrm{ft}$ ), and failure to be present at the second experimental session (1).

Design. The design of this experiment was a 2 by 2 by 2 split-plot factorial (Kirk, 1968). There were two between-subjects variables: monocular or binocular presentation of the inspection stimuli and curvature or no curvature of the inspection stimuli. The single within-subjects variable was interocular or intraocular presentation of the test stimuli as opposed to the inspection stimulus (Figure 1). Each subject participated in one level of each between-subjects variable and both levels of the within-subjects variable.

Apparatus. The viewing apparatus was a mirror stereoscope. The stimulus slides were projected onto a translucent rear-projection screen using a gravity feed slide projector (Kodak Ektagraphic B-2). The rear-projection screen was placed at a distance of $1.83 \mathrm{~m}$ from the subject. The response apparatus consisted of two buttons (one red. one black) which, when pushed by the subject, caused a red or green light on the experimenter's console to be activated. This apparatus is described in more detail elsewhere (Vernoy, 1975).

Stimuli. Figure 1 shows the inspection and test stimuli used in this experiment. Each subject in each trial viewed a combination of two curved lines and a fixation dot, which, when fused in the stereoscope, portrayed a curved line pair either concave or convex toward a central fixation dot. The radius of curvature of all the inspection curves was equal to $3.13 \mathrm{~m}$. All the test stimuli, when fused in the stereoscope. portrayed either straight-line pairs or curved-line pairs with radii of curvature equal to $3.99,4.73,5.43$, or $6.09 \mathrm{~m}$.

In the practice trials, the inspection stimulus was a dark dot on a light background. The dot had a diameter of $5 \mathrm{~cm}$. The test stimuli for the practice trials were curved line pairs similar to those used in the experimental conditions. except that all the curves had a radius of curvature equal to $3.38 \mathrm{~m}$.

All the stimuli in this experiment, except the practice inspection stimulus, were white lines on a dark background. The luminance of the white lines was $1.71 \mathrm{~cd} / \mathrm{m}^{2}$ and the luminance of the dark background was $.048 \mathrm{~cd} / \mathrm{m}^{2}$. The length of each white arc or line was $71 \mathrm{~cm}$.

Procedure. Each subject participated in two 1-h experimental sessions, separated by 1 week. The subject's visual acuity was tested (Bausch \& Lomb direct reading test chart) at the beginning of each session.

Each subject participated in at least one 3 -min practice trial before each session. The practice trial began with a 3-min fixation period during which the subject viewed a large dark dot; then a high-pitched tone was sounded to signal the end of the fixation period and the beginning of the presentation of the test stimuli. The subject's task was to respond once to each of the test stimuli by pressing the red button if the lines appeared bowed out away from the fixation point (convex) and the black button if the lines appeared bowed in toward the fixation point (concave).
The subject was first pretested with and required to respond to the nine test stimuli. The subject was then instructed that he would be viewing two lines and a central fixation dot for $10 \mathrm{~min}$. The subject was instructed to fixate on the central dot until a high-pitched tone was sounded to signal the end of the 10 -min fixation period and the beginning of the presentation of the test stimuli. The nine test stimuli were presented in a random order for $2 \mathrm{sec}$ each with an interstimulus interval of $1 \mathrm{sec}$, during which the subject responded as he had been instructed in the practice trial.

There was a 3-min rest period between experimental conditions, during which the subject waited in total darkness. Each subject participated in four 10-min experimental trials in each of two experimental sessions. Each combination of inspection stimulus and test stimulus type was presented once to each subject in a completely counterbalanced order over the two experimental sessions.

\section{Results}

The dependent variable in this experiment was the degree of curvature ( 1 /radius of curvature) of the most curved test stimulus which was reported by the subject to be curved opposite to its physical curvature. Straight test stimulus lines were treated as lines curved in the same direction as the inspection stimulus and having a radius of curvature equal to $600 \mathrm{~m}$ (the smallest curvature which would produce a straight line when projected onto the rear-projection screen). For instances where the most oppositely curved stimulus represented an aftereffect in the wrong or counteradaptive direction, the dependent variable score was given a minus sign. When the subject reported all directions of curvature correctly, he was assigned a dependent variable score of zero. The data used for calculations and statistical analysis in this experiment were the differences between the pretest and posttest dependent variable measures. The proportion of concave judgments as a function of curvature of test stimuli is presented in Table 1. For ease of presentation of the experimental data, approximate radii of curvature will be reported instead of the degree of curvature values used in the statistical analysis. A three-way analysis of variance showed the main effect of interocular or intraocular presentation of the test stimuli, $F(1,36)=6.13$, $\mathrm{p}<.05$, and the main effect of curvature or no curvature of the inspection stimulus, $F(1,36)=$ 
Table 1

Experiment I: Proportion of Concave Judgments as a Function of Curvature of Test Stimuli

\begin{tabular}{|c|c|c|c|c|c|c|c|c|c|c|c|c|c|c|c|c|c|c|}
\hline \multirow[b]{3}{*}{ Stimuli } & \multicolumn{18}{|c|}{ Curved Inspection Stimuli } \\
\hline & \multicolumn{9}{|c|}{ Pretest* } & \multicolumn{9}{|c|}{ Posttest* } \\
\hline & 3.99 & 4.73 & 5.43 & 6.09 & St. & -6.09 & -5.43 & -4.73 & -3.99 & 3.99 & 4.73 & 5.43 & 6.09 & St. & -6.09 & -5.43 & -4.73 & -3.99 \\
\hline \multirow{2}{*}{\multicolumn{19}{|c|}{$\begin{array}{l}\text { Monocular } \\
\text { Interocular }\end{array}$}} \\
\hline & & & & & & & & & & & & & & & & & & \\
\hline Concave & 1.0 & 1.0 & 1.0 & 0.9 & 0.5 & 0.0 & 0.0 & 0.0 & 0.0 & 1.0 & 1.0 & 0.9 & 0.8 & 0.1 & 0.0 & 0.0 & 0.0 & 0.0 \\
\hline Convex & 1.0 & 1.0 & 1.0 & 1.0 & 0.5 & 0.0 & 0.0 & 0.0 & 0.0 & 1.0 & 1.0 & 1.0 & 0.9 & 0.8 & 0.1 & 0.2 & 0.1 & 0.0 \\
\hline \multicolumn{19}{|l|}{ Intraocular } \\
\hline Concave & 1.0 & 1.0 & 1.0 & 1.0 & 0.4 & 0.1 & 0.0 & 0.0 & 0.0 & 1.0 & 1.0 & 0.8 & 0.8 & 0.0 & 0.1 & 0.0 & 0.0 & 0.0 \\
\hline Convex & 1.0 & 1.0 & 1.0 & 1.0 & 0.6 & 0.1 & 0.0 & 0.0 & 0.0 & 1.0 & 1.0 & 1.0 & 1.0 & 0.9 & 0.2 & 0.1 & 0.0 & 0.1 \\
\hline \multirow{2}{*}{\multicolumn{19}{|c|}{ Binocular }} \\
\hline & & & & & & & & & & & & & & & & & & \\
\hline Concave & 1.0 & 1.0 & 1.0 & 1.0 & 0.5 & 0.0 & 0.0 & 0.0 & 0.0 & 1.0 & 1.0 & 0.9 & 0.9 & 0.2 & 0.0 & 0.0 & 0.0 & 0.0 \\
\hline Convex & 1.0 & 1.0 & 1.0 & 0.9 & 0.5 & 0.0 & 0.0 & 0.0 & 0.0 & 1.0 & 1.0 & 1.0 & 1.0 & 1.0 & 0.1 & 0.1 & 0.0 & 0.0 \\
\hline \multicolumn{19}{|l|}{ Intraocular } \\
\hline Concave & 1.0 & 1.0 & 1.0 & 1.0 & 0.4 & 0.0 & 0.0 & 0.0 & 0.0 & 0.9 & 0.8 & 0.8 & 0.7 & 0.0 & 0.0 & 0.0 & 0.0 & 0.0 \\
\hline Convex & 1.0 & 1.0 & 1.0 & 1.0 & 0.5 & 0.0 & 0.0 & 0.0 & 0.0 & 1.0 & 1.0 & 1.0 & 1.0 & 0.9 & 0.3 & 0.1 & 0.0 & 0.1 \\
\hline
\end{tabular}

Note. The data from the straight inspection figures show no change from pretest to posttest, therefore they are omitted from this table.

${ }^{*}$ Radius of curvature of test stimuli in meters: the minus size indicates convex curvature.

$15.40, \mathrm{p}<.01$, to be the only significant factors. The mean negative aftereffect (radius of curvature of $27.80 \mathrm{~m}$ ) for the intraocular conditions was greater than the mean negative aftereffect for the interocular conditions (radius of curvature of $83.83 \mathrm{~m}$ ), the larger radius of curvature indicating less adaptation. The mean negative aftereffect radius of the curved inspection stimuli of $21.87 \mathrm{~m}$ indicated significantly greater adaptation than the mean negative aftereffect radius of $524.24 \mathrm{~m}$ for the straight inspection stimuli.

Total perceptual adaptation in this case would mean that, after the 10 -min adaptation period in a curvature condition, the subject would perceive the inspection stimulus curves as straight lines. Subsequently, the subject should perceive the curvature of the straight test lines to be equal to the physical curvature of the inspection stimulus lines, but in the opposite direction. The mean dependent variable measurement in the intraocular-curved condition was equivalent to $19 \%$ of the aftereffect expected from total perceptual adaptation. There was a $9 \%$ aftereffect recorded in the interocular condition.

\section{Discussion}

The results show that adaptation to oppositely curved lines in noncorresponding parts of the same or different retinas occurs in human subjects. There is an interocular transfer of this adaptation amounting to $47 \%$ of the intraocular adaptation. One possible explanation for these results is differential adaptation of curvature analyzers in the visual cortex. There is physiological evidence of curvature detectors in the frog (Lettvin, Maturana, McCulloch, \& Pitts, 1959). Riggs (1973) has recently demonstrated a curvature-dependent color aftereffect similar to that of McCollough (1965). This curvature-dependent aftereffect is evidence for some type of color-coded curvature detectors either in the retina or in the visual cortex. Microelectrode studies of the primate visual cortex have reported physiological evidence of both line detectors and curvature detectors (Hubel \& Wiesel, 1968). If it is true that curvature detectors are dependent on the output of cortical line detectors, then these curvature detectors must also be found in the visual cortex. If there are, indeed, curvature detectors in the cortex which are maximally tuned to a certain orientation and curvature, then adaptation to the curved inspection stimuli in this experiment could be the result of the adaptation of certain of these curvature detectors.

The subject was instructed to fixate on the dot between the inspection lines in all experimental conditions in this experiment. Because the individual eye movements of each subject were not monitored during the experiment, it could be argued that the subjects may have actually moved their eyes. Therefore, it is possible that the subjects might have adapted to the curvature of the inspection lines by the use of eye movements, as postulated by Coren and Festinger (1967). They postulated that curved lines are first perceived as more curved than they actually are. This misperception or curvature illusion causes the subject to fail to correctly scan the curves with his eyes. The subject initially overshoots the end points of the curve. He then recalibrates his eye movements, causing an apparent adaptation to the curvature. However, when two curves of opposite curvatures are presented to a subject, the subject would have to scan both the lines separately in order to adapt to the curvature in both lines. The subject might direct his 


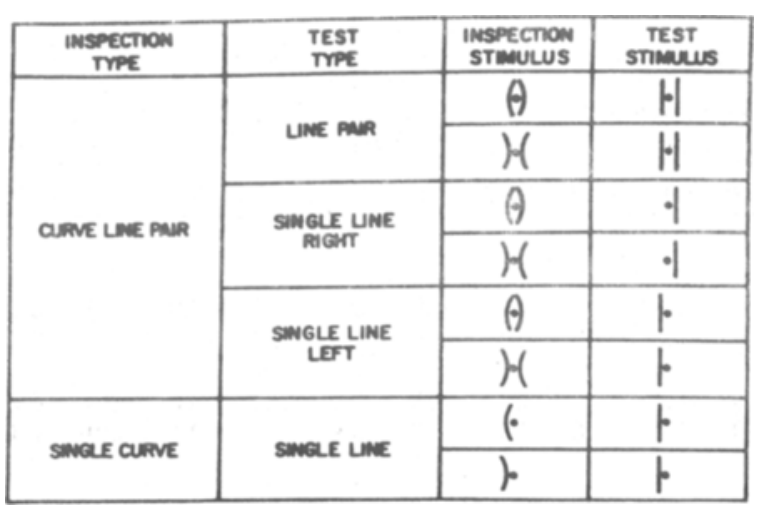

Figure 2. Experimental utimuli used in Experiment II. (Additional teat atimull were curved lines in the same positions as the straight lines whown in the figure.)

gaze to one of the curves and scan that curve for some minimum amount of time and then reorient his gaze in order to scan the other curve. In this manner, the subject could recalibrate his eye movements to one line, and then to another. In order to show simultaneous adaptation to both curves, the subject must then exhibit some kind of eye positioncontingent adaptation. A subject might also scan the curved lines but not bring them separately into the fovea. Both of the above scanning techniques have the same difficulty in that this scanning may cause counteradaptation to the line not presently being tracked.

A possible difficulty in the first experiment is that a subject might appear to have adapted to both curves when he has actually adapted to only one curve on the basis of eye movements. According to this explanation, the subject would choose one of the inspection curves for adaptation. This curve would begin to appear straight, while the other would continue to appear curved. This adaptation would cause the pairs of straight test lines to appear as one straight line and one curved line, therefore allowing the subject to respond as if he had adapted to both the curves in the inspection stimulus. If a situation is created in which the test stimuli are not line pairs but single lines placed either to the left or right of a fixation dot, a different result is expected. If the test stimulus were a single line, and the adapted inspection curve were randomly selected, there would be a .5 probability of the test stimulus being on the same side of the fixation dot as the adapted inspection curve. Therefore, the subject will respond in an adaptive manner if the single test stimulus is on the same side of the fixation dot as the chosen curve in the inspection stimulus, but the subject will respond at a chance level if the test stimulus line is on the opposite side of the fixation dot. Given the above conditions, the probability that a subject makes an adaptive response after adapting to only one of the curves in the inspection stimulus by eye movements is .75 .
If curvature adaptation is selective adaptation of neural curvature analyzers which are maximally sensitive to a certain orientation and degree of curvature, then there should be no difference in responses to test stimuli portraying single or double lines when the inspection stimulus is a curved line pair. The hypothesis tested in Experiment II was that the difference between adaptive responses made to a line pair test stimulus and a single line test stimulus when the inspection stimulus is a curved line pair will be less than the .25 value predicted by the hypothesis that the subject adapted to only one of the inspection curves.

\section{EXPERIMENT II}

\section{Method}

Subjects. The subjects were 11 introductory psychology students who participated in this experiment to fulfill a course requirement. One subject was dropped because of equipment failure.

Design. There were four experimental conditions in this experiment (Figure 2). One condition is similar to Gibson's (1933) original experiment, a single inspection line with a single test stimulus. In the other three conditions. the inspection stimulus was a curved line pair and the test stimulus was: (a) a line pair separated by a fixation dot, (b) a line to the right of the fixation dot, or (c) a line to the left of the fixation dot.

Apparatus. The apparatus was identical to that used in Experiment I, except that the left eye viewing port on the stereoscope was occluded. The subject was able to view only the right half of the rear-projection screen.

Stimuli. Figure 2 depicts the inspection and test stimuli used in this experiment. The inspection stimuli were curved line pairs, concave or convex toward a central fixation dot, or a single curved line to the left or right of a central fixation dot. The radius of curvature of all inspection stimulus curves was $3.13 \mathrm{~m}$.

The test stimuli were line pairs separated by a central fixation dot or a single line to the left or to the right of a central fixation dot. The test stimuli lines were straight lines (equal to a radius of curvature of $600 \mathrm{~m}$ ) or curves with radii of curvature of $3.99,4.73$, 5.43, or $6.09 \mathrm{~m}$. Each curved test stimulus was either concave or convex toward the fixation dot.

The practice inspection stimulus was a large dark dot on a light background. The practice test stimuli were all curved line pairs separated by a central fixation dot or single curved lines, either concave toward or convex toward a central fixation dot. Each of the practice test stimuli had a radius of curvature of $3.38 \mathrm{~m}$.

All stimuli, except the practice inspection stimulus, were white lines on a dark background. The luminance of the white lines was $1.71 \mathrm{~cd} / \mathrm{m}^{2}$ and the luminance of the dark background was $.048 \mathrm{~cd} / \mathrm{m}^{2}$. The length of each white line or arc was equal to $71 \mathrm{~cm}$.

Procedure. The procedure was identical to that of Experiment I except that the subjects participated in only one experimental session.

\section{Results}

The first dependent variable was again the degree of curvature of the most curved test stimulus that was reported by the subject to be curved opposite to its physical curvature. There were no significant differences between any of the experimental groups. The second dependent variable used in this experiment was the proportion of adaptive responses made to the individual test stimuli. The mean 
Figure 3. An example of a random-dot stereogram used in Experiment III. (When fused in a stereoscope, this stereogram portrays a line curved towards the vewer.)
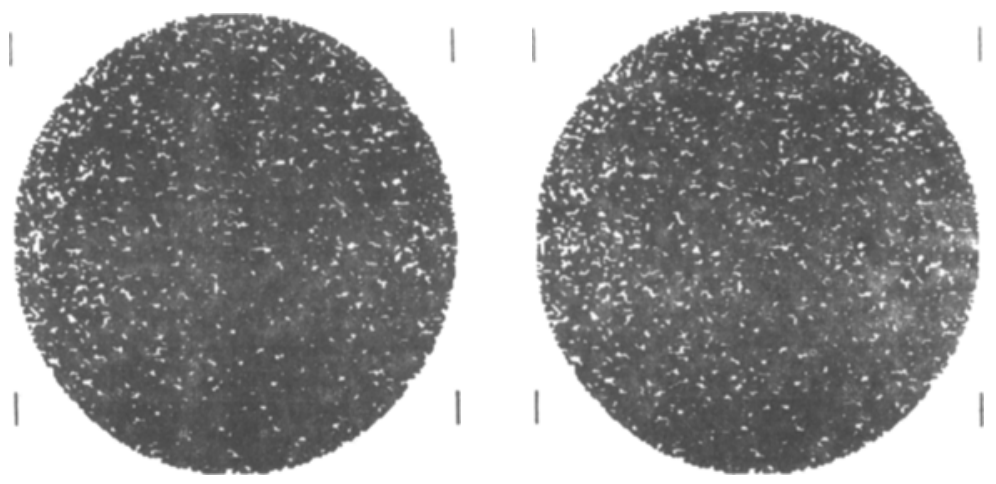

proportion of adaptive responses to the straight line pair test stimulus after viewing a curved line pair inspection stimulus was 1.00 . The mean proportion of adaptive responses to the single straight line test stimulus after viewing a curved line pair inspection stimulus was .9. The obtained difference of .1 was significantly less than the predicted difference of .25 , $t(9)=-4, p<.01$, and the obtained difference was not significantly greater than zero, $t(9)<1, \mathrm{p}\rangle .05$.

\section{Discussion}

The results of this experiment did not show significant differences between any of the experimental conditions. If, indeed, adaptation to curvature is the result of adaptation to broadly tuned neural analyzers in the cortex, then there is no reason to expect more adaptation in the single-inspection/ single-test condition. But if adaptation to curvature is a function of recalibrated eye movements, then less adaptation might be expected to two opposite inspection curves than to a single inspection curve. There are three reasons to expect a decrement in the level of curvature adaptation with increased number of curves if the eye-movement theory is assumed: (a) The total tracking time must be divided among both curves present. (b) There must be eye movements in different directions which may have the effect of cancelling out any previous adaptation. (c) In order for this adaptation to be present, the eye must track the curve during the test period, but the eye cannot track both curves at once. But adaptation to more than one curve in the visual field was found, and the amount of adaptation to two curves was not as different from adaptation to a single curve as predicted by the eye-movement hypothesis.

The results of the above experiments do not support an eye-movement theory of adaptation to curvature; but the data presented do not clearly indicate whether this adaptation takes place in the retina or at some other level in the visual information processing system. It is possible to generate random-dot stereogram patterns which contain no figural information at a retinal level (Julesz, 1964).
Adaptation to curved lines portrayed as random-dot stereograms would indicate a central rather than peripheral locus for adaptation to curvature. Gibson (1933) has demonstrated that adaptation to curvature occurs when the curve is portrayed by dots. Blakemore and Julesz (1971) have shown that it is possible to record adaptation and a subsequent negative aftereffect to random-dot stereogram images. Experiment III was conducted to measure perceptual adaptation to curvature in curves portrayed by random-dot stereograms.

\section{EXPERIMENT III}

\section{Method}

Subjects. The subjects were 40 introductory psychology students who took part in this experiment as part of a course requirement. Additional subjects (5) were run or partly run, but had to be dropped due to failure to follow instructions (3). failure to have $20 / 40$ visual acuity (Bausch \& Lomb direct reading test chart $20 / 20$ line at $10 \mathrm{ft}$ ) (1), and double vision (1).

Design. The design of this experiment was a 3 by 2 by 2 split-plot factorial (Kirk. 1968). There were two between-subjects variables, type of stereogram and type of disparity. There were two levels on the stereogram variable, random-dot or line stereogram; and two levels of disparity. crossed or uncrossed. The within-subjects variable had three levels $(x, y, z)$. Each subject participated in one level of each between-subjects variable and all levels of the within-subjects variable.

Apparatus. The apparatus was identical to that used in Experiment 1 .

Stimuli. There were two basic types of stimuli, random-dot stereograms (Figure 3) and line stereograms. The random-dot stereograms were computer-generated random-dot stereo pairs which. when fused, portrayed random-dot lines curved concave to the subject's right ( $x$ type), concave up ( $y$ type), or concave toward the subject ( $z$ type). These curves appeared to float in front of or behind the random-dot background. The width of each random-dot curve was equal to 10 texture elements $(1 \mathrm{~cm})$. The line stereagrams were computer-generated line stereo pairs which. when fused. portrayed white lines curved concave to the subject's right ( $x$ type). concave up ( $y$ type), or concave toward the subject ( $z$ type). These white lines appeared to float in front of or behind a dark background. The length of an imaginary chord connecting the endpoints of any of the curves (random-dot or line) would equal $78 \mathrm{~cm}$. The stereo pairs were presented with either a four-element temporal or a four-element nasal disparity. The luminance of the white lines or the white dots was $16.31 \mathrm{~cd} / \mathrm{m}^{2}$. The luminance of the dark background or dark dots was $.013 \mathrm{~cd} / \mathrm{m}^{2}$. 
Table 2

Experiment III: Proportion of Concave (Left, Up, Toward) Judgments as a Function of Curvature of Test Stimuli

\begin{tabular}{|c|c|c|c|c|c|c|c|c|c|}
\hline $\begin{array}{l}\text { Type of } \\
\text { Stereo- } \\
\text { gram }\end{array}$ & 1.57 & 3.14 & 4.71 & 6.28 & St. & -6.28 & -4.71 & -3.14 & -1.57 \\
\hline & \multicolumn{9}{|c|}{ Pretest* } \\
\hline \multicolumn{10}{|c|}{ Random Dot } \\
\hline $\mathbf{x}$ & 1.0 & 1.0 & 1.0 & 0.90 & 0.55 & 0.10 & 0.05 & 0.0 & 0.0 \\
\hline$y$ & 1.0 & 1.0 & 0.95 & 0.85 & 0.40 & 0.05 & 0.0 & 0.0 & 0.0 \\
\hline z & 1.0 & 1.0 & 0.95 & 0.90 & 0.45 & 0.05 & 0.05 & 0.0 & 0.0 \\
\hline \multicolumn{10}{|l|}{ Line } \\
\hline $\mathrm{x}$ & 1.0 & 1.0 & 0.95 & 0.95 & 0.50 & 0.05 & 0.05 & 0.0 & 0.0 \\
\hline$y$ & 1.0 & 1.0 & 1.0 & 1.0 & 0.45 & 0.05 & 0.0 & 0.0 & 0.0 \\
\hline$z$ & 1.0 & 1.0 & 0.95 & 0.95 & 0.55 & 1.0 & 0.0 & 0.0 & 0.0 \\
\hline & \multicolumn{9}{|c|}{ Posttest* } \\
\hline \multicolumn{10}{|c|}{ Random Dot } \\
\hline $\mathrm{x}$ & 1.0 & 1.0 & 0.95 & 0.95 & 0.95 & 0.45 & 0.25 & 0.15 & 0.0 \\
\hline$y$ & 1.0 & 1.0 & 0.90 & 0.85 & 0.85 & 0.15 & 0.10 & 0.0 & 0.0 \\
\hline$z$ & 1.0 & 1.0 & 0.90 & 0.80 & 0.85 & 0.15 & 0.15 & 0.0 & 0.50 \\
\hline \multicolumn{10}{|l|}{ Line } \\
\hline $\mathrm{x}$ & 1.0 & 1.0 & 0.95 & 0.85 & 0.90 & 0.10 & 0.10 & 0.0 & 0.0 \\
\hline$y$ & 1.0 & 1.0 & 0.90 & 0.85 & 0.85 & 0.15 & 0.15 & 0.0 & 0.0 \\
\hline z & 1.0 & 1.0 & 0.95 & 0.90 & 0.95 & 0.60 & 0.50 & 0.40 & 0.10 \\
\hline
\end{tabular}

Note. Because there was no significant difference between disparity levels they are combined in this table.

*Test stimulus radius in meters; the minus signs indicate convex curvature (left. up, towards).

The experimental inspection stimuli portrayed curved lines of the $x, y$, or $z$ type. The radius of curvature of the inspection curve was equal to $.78 \mathrm{~m}$. The test stimuli consisted of one straight line stereogram and stereograms portraying lines curved in the same plane as the inspection stimulus with radii of curvature equal to $1.51 .3 .14,4.71,6.28,-1.51,-3.14,-4.71$, and $-6.28 \mathrm{~m}$ (a minus sign indicates curvature concave to the left of the subject, concave down or concave away from the subject). The test stimuli for a given experimental condition all had the same type of disparity (i.e., temporal or nasal) as that of the inspection stimuli.

In each practice condition, the inspection stimulus was a stereogram of a dark dot on a light background. The diameter of the dot subtended $5 \mathrm{~cm}$. There were 10 test stimuli in each practice condition. The radius of curvature of each practice test curve was either .65 or $-.65 \mathrm{~m}$. Five of the practice test stimuli had crossed disparity and five had uncrossed disparity.

In the random-dot stereogram conditions, there were eight training stimuli. These were computer-generated random-dot stereograms portraying a square, a circle, a plus, or a ring in depth, each with temporal or nasal disparity.

Procedure. Each subject participated in one 1-h experimental session. The subject's eyesight was tested (Bausch \& Lomb direct reading test chart) at the beginning of each experimental session. A subject in the random-dot stereogram condition was also tested for ability to fuse and resolve stimuli presented as random-dot stereograms. The subject was required to view all eight random-dot stereogram training stimuli and to describe the figure portrayed in the stereogram and indicate whether the figure was in front of or behind the random-dot background.

The experimental procedure for both the random-dot stereogram conditions and the line stereogram conditions were similar. The subject participated in at least one 3-min practice trial before each experimental condition. If the subject responded correctly to the stimuli at the end of the practice trial, then the experimental condition was begun. If the subject responded incorrectly or in any way failed to follow instructions, the instructions were again read to the subject and the practice trial was repeated.

The subject was first pretested with and required to respond to the nine test stimuli. The subject was then instructed that he would be viewing a single curved line in the experimental condition. The subject was instructed to fixate on the curve for $10 \mathrm{~min}$. At the end of $10 \mathrm{~min}$, a high-pitched tone was sounded to signal the end of the fixation period and the beginning of the presentation of the test stimuli.

The test stimuli in the random-dot stereogram conditions were presented in a random order for $15 \mathrm{sec}$ each with an interstimulus interval of $1 \mathrm{sec}$. The subject's task was to respond to each of the test stimuli once by pressing the red button if the test curve appeared concave to the right or concave upward or concave away from the subject, and to push the black button if the test curve appeared concave to the left or concave downward or concave toward the subject.

There was a 3 -min rest period between experimental conditions during which the subject was instructed on how to respond in the next experimental condition. Each subject participated in all three levels of type of curvature in only one of the following conditions. random-dot stereo nasal disparity, random-dot stereo temporal disparity. line-stereo nasal disparity, or line-stereo temporal disparity.

\section{Results}

The dependent variable was the same as that used in Experiment $\mathrm{I}$. The proportion of concave judgments as a function of curvature of test stimuli is presented in Table 2 . A 2 by 2 by 3 analysis of variance showed the main effect of type of curvature. $F(2,72)=8.16, p<.01$, as well as the interaction of type of curvature with type of stereogram, $F(2,72)=$ $7.44, \mathrm{p}<.01$, to be significant. Overall mean adaptation to the stimuli curved in the $\mathrm{z}$ type was greater than that of either the $x$ or $y$ types. In the random-dot stereogram half of the experiment, however, mean adaptation of the $x$-type curves was greater than adaptation to the z-type curves, while in the line stereogram conditions, the z-type curvature adaptation level was by far the greatest. The mean adaptation level of each of the separate conditions was significantly greater than zero (Table 3 ). 


\section{Discussion}

Significant adaptation to curvature was observed in all conditions of this experiment. The random-dot stereograms portrayed the curves using only differential disparities of individual texture elements making up the random-dot matrix. The stereograms therefore contain no monocular or retinal information about the curves portrayed. This means that any processing of the curves portrayed by the random-dot stereograms must be central rather than retinal.

Several authors have shown that if there are curvature detectors in the cortex these curvature detectors must receive input from lower level line detectors (Blakemore \& Over, 1974; Crassini \& Over, 1975a, b; MacKay \& MacKay, 1974). If this is true, then it is also possible that these or similar curvature detectors can be driven by the disparity information in random-dot stereograms. Binocularly driven units or edge detectors have been reported in the cortex of both the monkey and the cat (Barlow, Blakemore, \& Pettigrew, 1967; Hubel \& Wiesel, 1968). Barlow, Blakemore, and Pettigrew (1967) reported that in the cat 112 out of 137 units investigated could be binocularly driven. It is therefore possible that curvature analyzers are not only driven by monocular edge detectors but also by binocular edge detectors which are sensitive to very small disparities in the visual field. The random-dot stereograms present the subject with an anomalous contour of a curved line which may be processed by the same binocular edge detectors which are responding to the curvature in the line stereograms. The adaptation recorded to the random-dot $\mathrm{x}$ and $\mathrm{y}$ types might then be the result of the adaptation of curvature analyzer units. The random-dot z-type adaptation, on the other hand, might be explained either by adaptation of these proposed curvature analyzers or by adaptation to the differential disparities used to portray the curve (Blakemore \& Julesz, 1971).

The mean adaptation for the line $z$ type was nearly twice as great as any of the other single conditions. This result may also be construed as evidence for selective adaptation of cortical curvature analyzers. A line stereogram which portrays a curve concave toward the subject ( $\mathrm{z}$ type) is composed of a right-eye view portraying a curve concave to the subject's right, and a left-eye view of a curve concave to the subject's left. When fused in a stereoscope, these separate views portray a line curved toward the subject. Therefore, there is a possibility that three separate sets of curvature analyzers are being adapted by this set of stimuli. Each eye's view might adapt some monocular curvature analyzers and the fused image is possibly adapting binocular curvature analyzers.

Results of Experiment $I$ indicate that when a curved line is presented to one eye only, there is some interocular transfer of curvature adaptation effects to
Table 3

Experiment III: Matched $t$ Tests Between Pretest and Posttest Dependent Variable Means

\begin{tabular}{|c|c|c|c|}
\hline \multirow{2}{*}{$\begin{array}{c}\text { Type of } \\
\text { Stereo- } \\
\text { gram }\end{array}$} & \multicolumn{2}{|c|}{$\begin{array}{l}\text { Radius of Curvature } \\
\text { (in Meters) }\end{array}$} & \multirow[b]{2}{*}{$t(9)$} \\
\hline & Mean Pretest & Mean Posttest & \\
\hline \multicolumn{4}{|c|}{ Random Dot } \\
\hline $\mathrm{x}$ & 540.6 & 9.3 & $4.23^{*}$ \\
\hline $\mathbf{y}$ & 570.3 & 34.8 & $7.54 *$ \\
\hline z & 570.2 & 6.8 & $4.36^{*}$ \\
\hline \multicolumn{4}{|l|}{ Line } \\
\hline $\mathrm{x}$ & 570.2 & 16.4 & $8.72^{*}$ \\
\hline$y$ & 570.3 & 13.5 & $3.83^{*}$ \\
\hline $\mathrm{z}$ & 540.6 & 2.6 & $4.23^{*}$ \\
\hline
\end{tabular}

${ }^{*} p<.01$

corresponding parts of the opposite eye. In the case of the $z$-type line curvature conditions, separate curves of opposite curvature were presented to corresponding parts of opposite eyes. Therefore, there would be monocular curvature adaptation to the curves in each eye, binocular curvature adaptation, and a small amount of interocular transfer of adaptation effects (which, in this case, would have a negative effect). The amount of adaptation found to the line $z$ type was approximately twice that found to either the line $x$ or line $y$ types. This amount of adaptation is consistent with the above hypothesis concerning adaptation to the curvature in line stereograms portraying a line curved in the zy plane.

\section{GENERAL DISCUSSION}

The results of Experiments I, II, and III indicate that adaptation to curvature can occur in inspection patterns consisting of curved line pairs, line stereograms, and random-dot stereograms. Experiments I and II indicate that it is possible for a subject to adapt to curvatures of different directions presented in different parts of the same or opposite retinas. These results are supportive of the neural curvature analyzer theory of adaptation to curvature. The other theory, based on eye movements, cannot adequately explain this result. Scanning of the curved lines to facilitate adaptation by recalibration of eye movements would cause the curves to be projected onto the fovea one at a time where counteradaptation to one curve during adaptation to another curve of opposite curvature might also occur.

The interocular transfer of adaptation found in Experiment I, together with the finding that adaptation to curves presented as random-dot stereograms in Experiment III, indicates a possible central locus for adaptation to curvature. The neural cortical curvature analyzer theory provides a better explanation of the results of these experiments than the eye-movement hypothesis. 


\section{REFERENCES}

Barlow. H. B.. Blakemore, C..\& Petrigrew. J. D. The neural mechanism of binocular depth discrimination. Journal of Physiology. 1967, 193, 327-342.

Blakemore, C., \& Julesz, B. Stereoscopic depth aftereffect produced without monocular cues. Science, 1971, 171, 286-288.

Blakemore, C..\& OVER, R. Curvature detectors in human vision? Perception, 1974, 3. 3-7.

Coltheart. M. Visual feature analyzers and aftereffects of tilt and curvature. Psychological Review, 1971, 78, 114-121.

Coren, S., \& Festinger. L. An alternative view of the "Gibson normalization effect." Perception \& Psychophysics. 1967, 2. $621-626$.

Crassini, B., \& Over, R. Curvature-specific color aftereffects. Perception \& Psychophysics, 1975, 17, 398-404. (a)

Crassinı, B.. \& Over, R. Masking, aftereffect, and illusion in visual perception of curvature. Perception \& Psychophysics. 1975, 17, 411-416. (b)

Gibson. J. J. Adaptation after-effect and contrast in the perception of curved lines. Journal of Experimental Psychology, 1933, 14, 1-31.

Hubel, D. H.. \& Wiesel, T. N. Receptive fields and functional architecture on monkey striate cortex. Journal of Physiology. 1968. 195. 215-243.

Julesz. B. Binocular depth perception without familiarity cues. Science, 1964, 145, 356-362.
KIRK. R. E. Experimental design: Procedures for the behavioral sciences. Belmont, Calif: Brooks/Cole, 1968.

Kohler, W.. \& Wallach, H. Figural after-effects: An investigation of visual processes. Proceedings of the American Philosophical Society, 1944, 88, 269-357.

Lettvin, J. T., Maturana, H. R., McCulloch, W. S., \& Pitts, W. H. What the frog's eye tells the frog's brain. Proceedings of the Institute of Radio Engineers, 1959, 47, 1940-1951.

MacKay, D. M. \& MACKaY, V. Do curvature-contingent chromatic aftereffects require "detectors for curvature"? Vision Research, 1974, 14, 1285-1287.

McCollough, C. Color adaptation of edge detectors in the human visual system. Science. 1965, 149. 1115-1116.

Over, R. Comparison of normalization theory and neural enhancement explanation of negative aftereffects. Psychological Bulletin, 1971, 75, 225-243.

Riggs, L. A. Curvature as a feature of pattern vision. Science, 1973. 181. 1070-1072.

Vernoy, M. W. Adaptation to curvature: An information processing approach. (Doctoral dissertation. University of California, Irvine, 1975). Dissertation Abstracts International. 1975, in press.

(Received for publication June 23, 1975; revision received October 6.1975. ) 